\title{
FULLY INVOLVED ENCLOSURE FIRES: EFFECTS OF FUEL TYPE, FUEL AREA AND GEOMETRY
}

Michael A.Delichatsios, and Gordon W.H. Silcock.

Fire SERT, University of Ulster

Jordanstown, BT37 0QB

Northern Ireland

\begin{abstract}
For the design of fire safety systems, evacuation analysis, structural response and external façade performance, the heat release rate history is a primary factor regarding the development of building fires starting from the room of fire origin. This work examines the steady state heat release rate period in enclosures that occurs after the initial growth period ends because either fire has spread to all fuel available or ventilation- controlled conditions have been established. It extends previous important work by identifying how fuel type (e.g. stoichiometric ratio), fuel surface area, room geometry and openings affect the rate of burning. Using recent well-designed experiments in cubic like enclosures and in corridors together with a simple theory, correlations are developed for the rate of pyrolysis, of incoming air flow and of excess pyrolysate. In the course of the analysis, critical areas of research are suggested concerning combustion efficiency, heat fluxes and effective fuel area involved in pyrolysis.
\end{abstract}

KEYWORDS: Enclosure fires, fully involved enclosure fires, burning rate, excess pyrolysate, air inflow, external wall flames.

\section{INTRODUCTION}

The present work was initiated from practical requirements to evaluate the performance of external facades in high rise buildings if flames extend out of windows from fully involved fires in an enclosure of a given floor. The height of these external flames together with their heat flux impact on the external wall determine the wall performance. The height of external flames depends on the excess pyrolysate which is the unburned fuel issuing from the enclosure fire below. Flames may extend outside of windows when an enclosure is fully involved in fire and usually in this case ventilation-controlled conditions prevail. Thus, it was decided to investigate the relationship that exists between pyrolysis rate and air inflow rate.

Review of the literature $[1,2]$ led to revisiting the physics of fully involved room fires.

Even though several experiments and relationships exist for the burning rate in fully involved enclosure fires [1,2], these results are not always consistent or complete. A significant complication in relation to the current situation is that enclosure heat losses due to the fire mask other effects such as effects of fuel type, fuel area and enclosure geometry (e.g. cubic like versus corridor).

Relying on recent experiments and analysis [3-10], a fresh attempt is made here to separate these controlling parameters and identify and suggest appropriate research needs. Geometry effects on air inflow rates have also been addressed analytically by Phil 
Thomas [11] including a reevaluation of heat loss terms. Additional selected references [12-15] prior to 1986 have discussed the augmentation of burning inside an enclosure in comparison to free burning.

The plan of this paper is as follows. First the motivation and physics are discussed through a simple model. This model is used to interpret experimental results reported for fires in cubic like enclosures and in corridors. Limitations and research needs are also identified.

\section{THE MOTIVATION, PHYSICS AND ANALYSIS}

\section{Motivation}

Prediction of detector, sprinkler and structural response depends on the selection of a heat release rate history from a fire in an enclosure of given geometry including openings and fuel load arrangement and distribution. This fire is called a design fire and consists of three parts shown schematically in Figure 1: a) a growing period represented for simplicity as t-square fire b) a steady state period and c) a decaying period represented as a sudden burnout for simplicity, when all fuel is consumed.

The growing period is the most difficult to predict because it depends on the type of the fuel, its configuration and distribution in the enclosure and the intensity of the ignition source. A steady state period occurs after all fuel surface area is involved in combustion. Figure 1 indicates that the steady state period can be fuel controlled or ventilation controlled. All fuel area could be involved if fire has contiguously spread over the available fuel area or if the heat flux conditions in the enclosure induce simultaneous pyrolysis and burning of all fuel area including the area away from the extent of contiguous fire spread. Even at ventilation controlled conditions, however, only part of the fuel area may be involved namely that fuel area over which sufficiently high heat fluxes apply to induce pyrolysis [9.10].

In this paper the focus is on the steady state burning period. Note that transition from the growing period to the steady state period may occur in different ways as Figure 1 indicates. For fuel controlled steady state conditions (case A of Fig.1), transition is smooth and occurs because fire has spread over the whole fuel area. However, for ventilation-controlled steady state conditions (case B of Fig. 1), sharp transitions can occur when: a) the oxygen concentration in the outgoing flow is zero (case B1), or b) heat fluxes in the enclosure are high enough to cause pyrolysis over sufficient fuel area (not necessarily all the fuel area if excessive) to create ventilation-controlled conditions (case B2). In reality, the transition is not sudden as shown in case B2 but it is much faster than the initial fire growth rate as increasingly more fuel area is involved in pyrolysis.

\section{Physics of steady state period heat release rate (HRR) a simple model}

During the steady burning period as shown in Fig.1 no further fire spread can occur regardless of how this steady state period is arrived at. The burning rate depends on the heat flux received from the flames and the hot gases inside the enclosure on one hand and the pyrolysis properties (such as heat of pyrolysis) and combustion properties (such as heat of combustion) of the burning material on the other hand. 


\section{$\underline{\text { Case A. Fuel controlled steady state }}$}

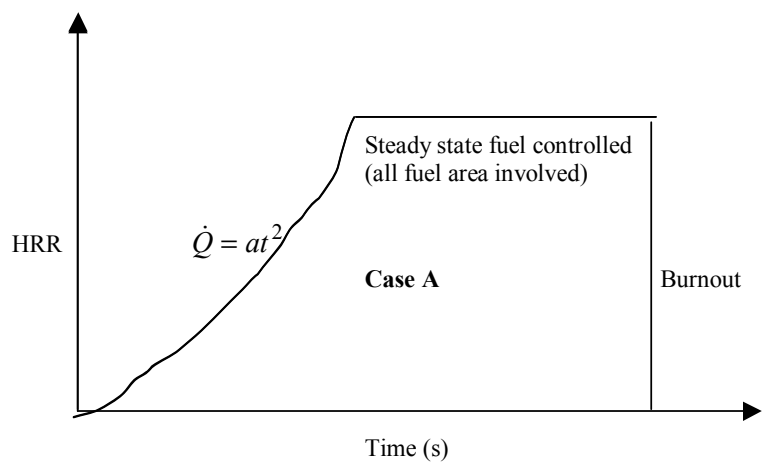

\section{Case B. Ventilation controlled steady fire: two cases}

Case B1: Transition due to Oxygen concentration becoming zero in the outflow

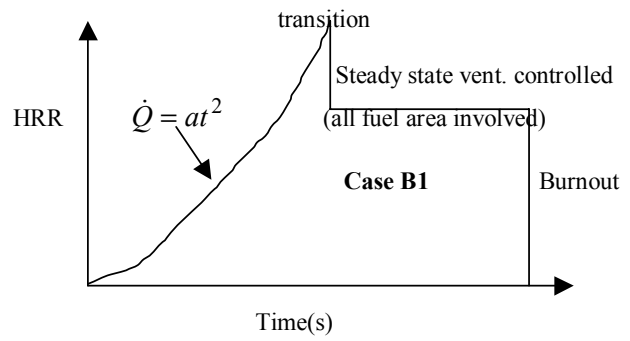

Case B2 : Transition due to critical heat flux from the hot layer

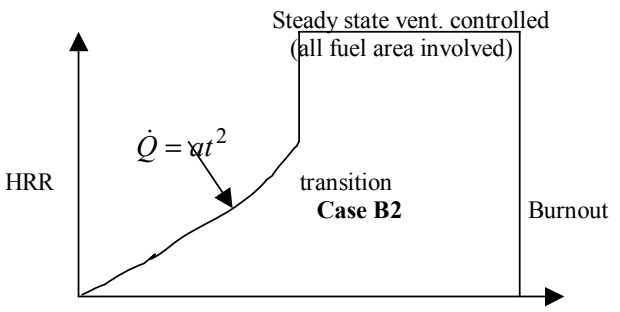

Time(s)

Figure 1 Heat release rate histories in enclosure fires. 
The heat fluxes from the flames to the surface depend on the combustion mode (e.g. non premixed or premixed) of the pyrolysing gases with the incoming air and the smoke-point of the fuel that can determine radiation feedback [16]. The heat fluxes to the fuel surface from the enclosure depend on its geometry and openings. In all cases, radiation blockage for large pool like fires should be considered in calculating the heat feedback to the fuel surface.

The expected burning behaviour for an actively involved fuel area $A_{F}$ is illustrated in Figure 2. In this case $A_{F}$ is fixed and equal to the minimum of a) the total available fuel area or b) the fuel area that is actively participating after ventilation conditions have been established. The ordinate is the pyrolysis rate normalized by the fuel area and the abscissa is the air inflow parameter, $A_{o} H_{o}{ }^{1 / 2}$, (also called opening ventilation factor) normalized by the fuel area. Two limiting regimes are noticeable in Fig.2. One, for large values of the abscissa, the enclosure is essentially open and the pyrolysis rate is constant namely similar to that of the fuel area burning in the open. The other, for small values of abscissa, burning is ventilation controlled as explained next and represented by the straight line through the origin in Figure 2. The straight line behaviour shows that the pyrolysis rate is proportional to the opening ventilation factor namely $\dot{m}_{F} \propto A_{o} H_{o}{ }^{1 / 2}$. Note that the air inflow $\dot{m}_{a}$ is also proportional to opening factor for nearly cubic enclosures $[1,2]$ :

$\dot{m}_{a}=0.5 A_{O} H_{0}^{1 / 2}$

which can be slightly improved to :

$\dot{m}_{a}=0.5 A_{O} H_{0}{ }^{1 / 2}-0.5 \dot{m}_{F}$

where $\dot{m}_{F}$ is the fuel pyrolysis rate. Here the mass flow rates are in $\mathrm{kg} / \mathrm{s}$ and all linear dimensions are in $\mathrm{m}$. This relation is based on the assumption that the temperature is uniformly distributed inside the enclosure, which nearly applies for cubic like enclosures. Additionally, the air inflow given by Equ.1 is a weak function of normally observed enclosure temperature having a range between $400 \mathrm{C}$ to $1000 \mathrm{C}$.

The region from free burning to ventilation controlled regime is shown by the free hand drawn curve in Figure 2. When moving from large values of the opening ventilation factor to smaller values, the burning rate increases as heat feedback from the enclosure hot gases to the fuel surface increases due to increasing gas temperatures inside the enclosure. The burning rate reaches a maximum value corresponding to the burning rate of a fuel mass that can react at stoichiometric conditions with the inflow air given by Equ. 1 as will be later verified from experimental measurements.

The normalization by the fuel surface area in Fig. 2 is deduced by using the energy balance equation in the enclosure at steady state conditions together with the energy balance for the fuel surface pyrolysis. A detailed discussion of the energy balances is included in reference [3]. 


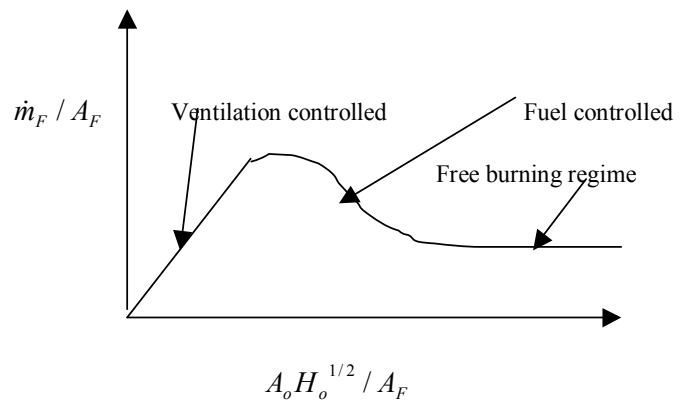

Figure 2 Expected behaviour of enclosure steady burning rate per unit surface area versus opening ventilation factor per unit surface area

For ventilation controlled conditions the main result can be written as [3]:

$\frac{\dot{m}_{F}}{\dot{m}_{a}}=\frac{3000 \chi_{A}-C_{p}\left(T_{g}-T_{o}\right)}{\Delta H_{v}+C_{p}\left(T_{g}-T_{p}\right)}$

$\frac{\dot{m}_{F}}{\dot{m}_{a}}=\frac{\dot{q}_{r}^{\prime \prime}}{\Delta H_{v}} \cdot \frac{1}{\dot{m}_{a} / A_{F}}$

The symbols are defined in the nomenclature. Equ.2a is an energy balance of the gas flows in and out of the enclosure whereas Equ.2b is an energy balance on the fuel surface. Note that in this derivation it is assumed that uniform temperatures exist in the enclosure and conduction losses through the walls and radiation losses through the openings are negligible. Heat losses to the walls vary with time, being initially proportional to the heat release rate, then decreasing as the surface wall temperature increases and finally attaining a steady value.

For fuel controlled but still uniform conditions in the enclosure, the following relation similar to Equ.2 applies:

$$
\begin{aligned}
\frac{\dot{m}_{F}}{\dot{m}_{a}} & =\frac{\left(\dot{m}_{F} / \dot{m}_{a}\right) \Delta H_{c} \chi_{A}-C_{p}\left(T_{g}-T_{o}\right)}{\Delta H_{v}+C_{p}\left(T_{g}-T_{p}\right)} \\
\frac{\dot{m}_{F}}{\dot{m}_{a}} & =\frac{\dot{q}_{r}^{\prime \prime}}{\Delta H_{v}} \cdot \frac{1}{\dot{m}_{a} / A_{F}}
\end{aligned}
$$

The new additional symbol here is the heat of combustion of the fuel $\Delta H_{c}(\mathrm{~kJ} / \mathrm{kg})$. 
The change from ventilation controlled to fuel controlled burning would occur when,

$$
\left(\dot{m}_{F}\right)_{\max }=\frac{\dot{m}_{a}}{S}
$$

and where also the pyrolysis rate has a maximum. Here $\mathrm{S}$ is the mass ratio of air to fuel for stoichiometric burning conditions.

As the opening ventilation factor increases beyond the point corresponding to Equ.4, the pyrolysis rate decreases as Figure 2 indicates. The decrease of the pyrolysis rate depends on configuration flow details such as for example the location of the fire source relative to the opening .that would affect the magnitude of heat flux feedback to the fuel surface.

The system of Equ. 2 or Equ. 3 is not complete for the determination of mass pyrolysis rate because the heat flux imposed on the fuel is not simply related to the gas temperature of the enclosure. If both flame heat fluxes and radiation blockage by the pyrolysis gases are ignored, the heat feedback can be approximated by,

$\dot{q}_{r}^{\prime \prime}=\sigma\left(T_{g}{ }^{4}-T_{p}{ }^{4}\right)$

Such a relation would apply for ventilation controlled and near the transition to fuel controlled conditions (see Figure 2) as specified by Equ. 4 .

Inspection of Equs. 2 or 3 together with Equ. 4 would indicate that the mass pyrolysis rate normalized by the fuel area should be a function of mainly two parameters shown in the following equation:

$\frac{\dot{m}_{F}}{A_{F}}=$ Function $\left(\frac{\dot{m}_{a}}{A_{F}}, S\right)$

This relation is more likely to be applicable in the ventilation-controlled regime including the maximum value of pyrolysis rate as shown in Figure 2. One should note that the fuel surface area in this relation is not necessarily the total fuel surface area but the surface area of the fuel over which the heat fluxes are sufficient to induce pyrolysis. It is hypothesized that the dependence on other parameters involved in Equations 2 or 3 is less important.

\section{APPLICABILITY AND VALIDITY OF EQU.5}

Equ.5 is used next to analyse and correlate experimental data in cubic like enclosures and corridors. In these experiments the fuel area is fixed and ventilation-controlled conditions are reached by decreasing the opening ventilation factor. In contrast, in wall lined enclosures (such as the ISO room corner test) the opening ventilation factor is fixed and ventilation- controlled conditions occur as the fire spreads to increasingly more fuel area.

\section{Experiments in nearly cubic geometry enclosure}

A set of comprehensive experiments are included in Ohmiya et.al.[4]. The experiments were conducted in an enclosure $1.8 \mathrm{~m}$ by $1.1 \mathrm{~m}$ by $1.1 \mathrm{~m}$ high as shown in Fig. 3 . The height of the opening was kept the same, $0.8 \mathrm{~m}$. The following opening widths were employed $0.4,0.6$ and $0.8 \mathrm{~m}$. The thermophysical properties of the tested fuels and the sizes of the fuel beds are included in table 1 . 
Table 1. Properties of tested fuels

\begin{tabular}{|l|l|l|l|l|}
\hline & Units & & & \\
\hline Fuel & & Methanol & PMMA & Wood \\
Surface Area, $\mathrm{A}_{\mathrm{F}}$ & $\mathrm{m}^{2}$ & $0.2,0.41,0.81$ & $0.22,0.42$ & $1.33,2.412 .62$ \\
$\begin{array}{l}\text { Latent heat, } \mathrm{kJ} \\
\text { Mass Stoichiometric air to } \\
\text { fuel ratio, } \mathrm{S} \\
\text { Pyrolysis temperature, } \mathrm{T}_{\mathrm{p}}\end{array}$ & $\mathrm{K}$ & $\begin{array}{l}1170 \\
6.47\end{array}$ & $\begin{array}{l}8.28 \\
1630\end{array}$ & 5.7 \\
& 338 & 543 & 623 \\
\hline Ambient temperature, $\mathrm{T}_{\mathrm{o}}$ & $\mathrm{K}$ & 293 & 293 & 293 \\
\hline
\end{tabular}

Based on Equ.5, steady state mass pyrolysis rates are plotted in Fig. 4 where both the mass pyrolysis rate and the air inflow- ventilation parameter are normalized by the fuel area. Plotted in this way, the data correlate well for each of the three fuels over the ventilation-controlled regime, which corresponds to small values of the opening ventilation factor. In addition, the shape of mass pyrolysis plots is similar to the general behaviour of the plot in Figure 2 including data beyond the maximum measured pyrolysis rate. The following relation is obtained from Fig. 4 for the ventilation-controlled regime regardless of fuel type:

$\frac{\dot{m}_{F}}{A_{F}}=0.1 \frac{A_{o} H_{o}{ }^{1 / 2}}{A_{F}}$

which agrees with the well known result by Kawagoe [1].

Using Equ.(1b) in Equ.6a, it follows that the (total) pyrolysis rate is related to the air inflow by:

$\dot{m}_{F}=0.22 \dot{m}_{a}$

Using the data from Fig. 4, Fig. 5a plots the maximum normalized pyrolysis rate versus the fuel rate corresponding to the stoichiometric value for the inflow air as given by the simplified form Equ.1a. A linear relation nearly passing through the origin is found in consistency with Equ.4.

A further examination of Fig. 5a shows that the maximum pyrolysis rate is nearly the same as if all the incoming air is consumed. This deduction is different from the common assumption that only part of the incoming air burns [2]. It agrees, however, with Tewarson's experiments for ventilation controlled (under ventilated) diffusion flame conditions in enclosures (Tewarson, [5], see Fig. 3.4.28). Some new experiments for ventilation controlled fires (Ohmiya et.al. [6]) also support this conclusion, as discussed at the end of this section. 


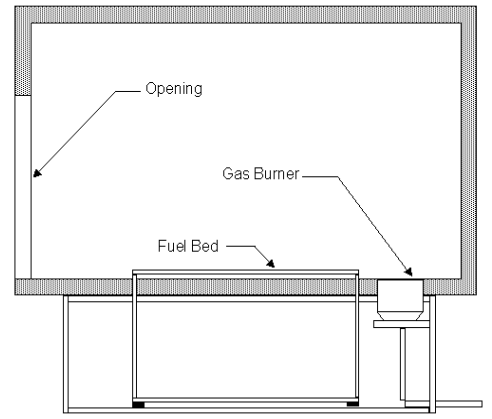

Figure 3 Diagram o f enclosure [4] with dimensions $1.8 \mathrm{~m} \times 1.1 \mathrm{~m} \times 1.1 \mathrm{~m}$ and openings of height $0,8 \mathrm{~m}$ and widths $0.8,0.6$ and $0.4 \mathrm{~m}$. Gas burner is used as igniter.

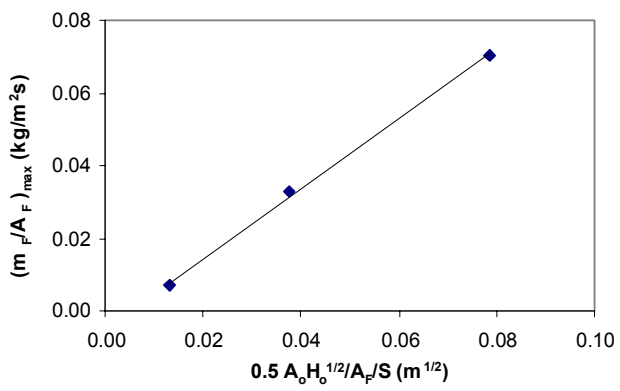

Figure 5a Maximum mass pyrolysis rate per unit fuel area versus stoichiometric fuel consumption at the the corresponding air inflow per unit fuel area.

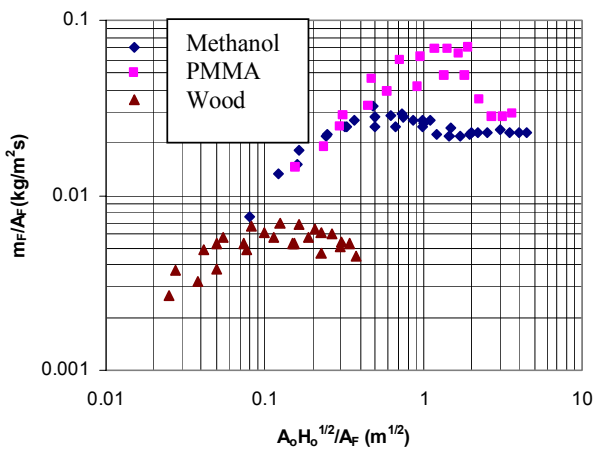

Figure 4 Correlation of mass pyrolysis versus opening ventilation factor for experiments listed in Table 1.

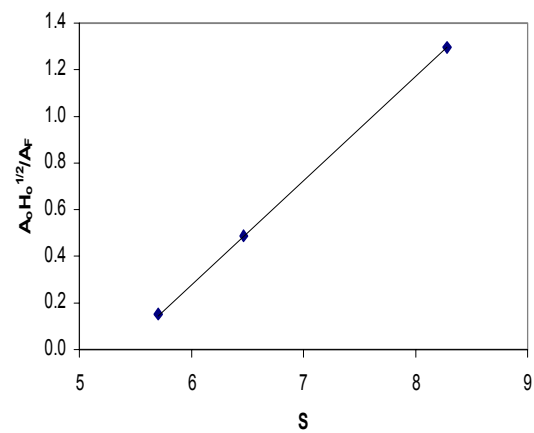

Figure 5b Ventilation Factor $(\sim$ air inflow) at maximum mass pyrolysis rate versus stoichiometric coefficient. 
From the preceding analysis, an expression is derived for the excess pyrolysate exiting the enclosure:

$$
\dot{m}_{e x}=\dot{m}_{F}-\frac{\dot{m}_{a}}{S} \quad \text { (6c)With the help of }
$$

Equ.6a, this expression can also be written as

$\dot{m}_{e x}=\left(0.22-\frac{1}{S}\right) \dot{m}_{a}$

which suggests that no excess pyrolysate exists if the stoichiometric ratio $\mathrm{S}$ is less than $1 / 0.22=4.54$.

Finally, Fig. $5 \mathrm{~b}$ plots the ventilation factor (proportional to air inflow rate) at the maximum pyrolysis rate, taken from Fig. 4, versus the stoichiometric air to fuel ratio, S. An almost linear correlation results having an intercept of about 5.4 on the $\mathrm{S}$ axis that can be fitted as:

$\frac{\dot{m}_{a}}{A_{F}} \propto \frac{A_{o} H_{o}{ }^{1 / 2}}{A_{F}}=0.46(S-5.4)$

Note that this is a preliminary result and valid only for $5.7<\mathrm{S}<8.28$ which is the range of fuels tested in Table 1 . This is quite an unexpected result that needs further investigation because, it is not clear how this result depends on fuel geometry, location of fire source in the enclosure and the free burning fuel behaviour.

Two comments elucidate critical points of the discussion:

1. A preliminary assessment of Equ.6e is deduced by using Equ.2b at the maximum pyrolysis rate to obtain that

$\frac{\dot{m}_{a}}{A_{F}}=\frac{\dot{q}_{r}^{\prime \prime}}{\Delta H_{v}} \cdot \frac{1}{\left(\dot{m}_{F} / \dot{m}_{a}\right)}=\frac{\dot{q}_{r}^{\prime \prime}}{\Delta H_{v}} S$

The difference between the experimental result, Equ.6e and the simple minded theoretical result, Equ.6f, is attributed to: a) variation with different fuels in the heat flux feedback from the flames and the enclosure and b) the possibility that the "effective" surface pyrolysis area is less than the total fuel area because heat feedback is not the same over the total fuel area. This behaviour has been observed in corridor fires when only part of fuel surface area is pyrolysing under ventilation controlled conditions $[9,10]$.

2. Applying an energy balance for the enclosure in recent experiments by Ohmiya [6] supports the observation that for ventilation-controlled conditions all incoming air is consumed as long as the enclosure gas temperature is not less than about $400 \mathrm{C}$ [6]. In these experiments the enclosure was $0.5 \mathrm{~m}$ by $0.5 \mathrm{~m}$ by $0.5 \mathrm{~m}$ and the opening was varied by changing its width and height. Heat release rate was kept fixed for each experiment since fire was produced by a constant flow rate methane porous-burner. Assuming that all incoming air is consumed inside the enclosure, an estimate of the steady state enclosure temperature is given by:

$$
\begin{aligned}
& 1500 A_{o} H_{o}{ }^{1 / 2}=\left(\dot{m}_{F}+.5 A_{o} H_{o}{ }^{1 / 2}\right) C_{p}\left(T_{g}-T_{o}\right)+\sigma\left(T_{g}{ }^{4}-T_{o}{ }^{4}\right) A_{o} \\
& +\left(k_{w} / \delta_{w}\right)\left(T_{g}-T_{o}\right)\left(A_{T}-A_{o}\right)
\end{aligned}
$$

This equation is an extension of Equ.2a and includes wall and radiation heat losses. 
The symbols are defined in the nomenclature. A confirmation of this relation is shown in Figure 6. The left hand side of Equ.6g is the heat release rate of the air consumed at optimum combustion efficiency inside the enclosure $\left(=3000 * 0.5 * A_{o} H_{o}{ }^{1 / 2}\right)$ and is used as abscissa in Fig.6 whereas the right hand side of Equ. $6 \mathrm{~g}$ calculated from the experimental data is the ordinate in Fig. 6 The first term on the right hand side is the convective heat coming out of the enclosure. The next term is the radiation losses through the opening. Finally the last term is the conduction losses through the walls. The outside temperature of the insulating walls is taken to be the same as the ambient

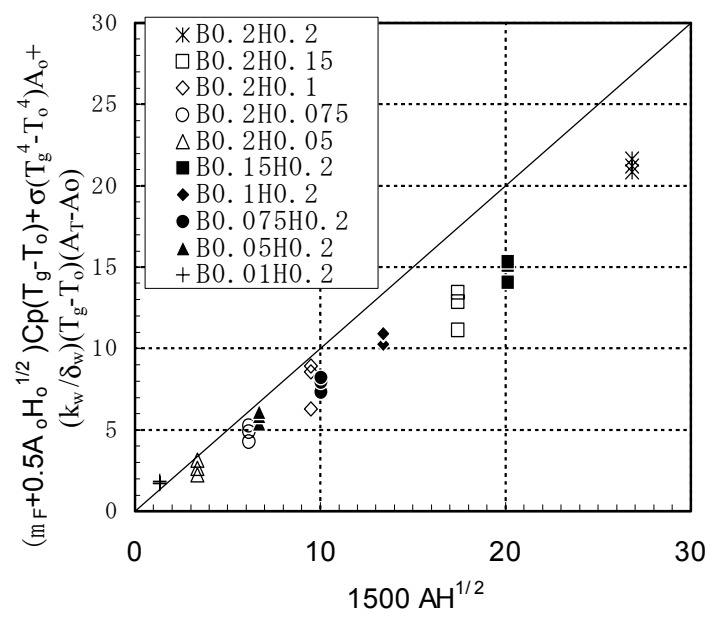

Figure 6. Energy balance for the enclosure in recent experiments by Ohmiya et al. [6]. In the insert of this Figure, $\mathrm{B}$ is the width and $\mathrm{H}$ the height of the enclosure in $\mathrm{m}$. (abscissa is the left and ordinate the right hand side of Equ. $6 \mathrm{~g}$ ).

\section{Effects of geometry: experiments in corridors}

There have been several experiments conducted recently related to the effects of room geometry or ventilation-opening geometry on the rate of burning in ventilation controlled fires (Miyazaki et al. [7], Thomas, [9], Cooke [10] ). Except for [7], these experiments do not provide enough data to develop an analysis similar to the analysis in the previous section.

The experimental setup is shown in Fig. 7 for a corridor $7.28 \mathrm{~m}$ long. $0.6 \mathrm{~m}$ wide and 0.9 $\mathrm{m}$ maximum height wherein heptane $\left(\mathrm{C}_{7} \mathrm{H}_{16}\right)$ pool fires centrally located were burned. The fuel pyrolysis rate was measured by using an overflow system. The ends of the corridor were fully open and changing the height of the corridor varied the ventilation factor. The ceiling and floor were constructed from an insulating material. Two fuel tray 
sizes were used $112 \mathrm{~cm}^{2}$ and $225 \mathrm{~cm}^{2}$. The latent heat of vaporization of heptane is 316 $\mathrm{kJ} / \mathrm{kg}$, its specific heat is $2.12 \mathrm{~kJ} / \mathrm{kg} \mathrm{K}$ and the stoichiometric ratio is 15.3 .

Figure 7 shows that the temperatures inside the corridor enclosure are not uniform as they are in a cubic like enclosure. There is a flaming area near the fire extending beyond the ceiling height for ventilation controlled conditions. A hot ceiling layer develops along the corridor and exhausts from the open ends of the corridor. Despite this significant difference of temperature distributions from cubic like enclosures, similar scaling relations as before are used to correlate the corridor pyrolysis and airflow data.

Fig. 8 shows a good correlation of the measured pyrolysis rates versus the opening ventilation factor where both are normalized by the fuel area as it was done in Fig. 4. The following result for the ventilation controlled regime derives from this figure:

$$
\frac{\dot{m}_{F}}{A_{F}}=0.025 \frac{2 A_{o} H_{o}{ }^{1 / 2}}{A_{F}}
$$

The factor 2 is due to the fact that air inflow occurs from both sides of the corridor. This means that the effective ventilation factor is $2 A_{o} H_{o}{ }^{1 / 2}$ for the corridor flow in Fig. 7. When Equ.7 is compared with Equ. 6a, it follows that fully involved ventilation controlled fires in corridors burn at a rate about $1 / 4$ the mass loss rate for nearly cubic enclosures for the same magnitude of opening ventilation factor. One reason for this behaviour is the nonuniform temperature distribution in corridors in contrast to cubic like enclosures wherein the temperature distribution is uniform. Thus, buoyancy forces driving the outflow and inflow are smaller in corridor flows than in cubic like enclosures. An estimate of the air inflow rate is possible using the result in the previous section that the maximum pyrolysis rate corresponds to stoichiometric burning conditions for the heptane fuel used in the present experiments. From this condition, one first gets the relationship:

$$
\left(\frac{\dot{m}_{F}}{A_{F}}\right)_{\max }=C\left(\frac{2 A_{o} H_{o}^{1 / 2}}{A_{F}}\right)_{\max } / S
$$

Then, using the respective data from Fig. 8 and the stoichiometric value for heptane $\mathrm{S}=15.3$, Eq.8a can be used to determine the constant $\mathrm{C}$

$$
\left(\frac{\dot{m}_{F}}{A_{F}}\right)_{\max }=0.27=C\left(\frac{2 A_{o} H_{o}{ }^{1 / 2}}{A_{F}}\right)_{\max } / S=C \cdot 20 / 15.3
$$

as $\mathrm{C}=0.20$ which allows the air inflow rate :to be found by:

$$
\dot{m}_{a}=0.20 \cdot(\text { ventilation factor })=0.20\left(2 A_{o} H_{o}{ }^{1 / 2}\right)
$$

Note that the coefficient 0.2 is considerably reduced compared with the corresponding coefficient 0.5 in Equ. 1 for nearly cubic enclosures. 


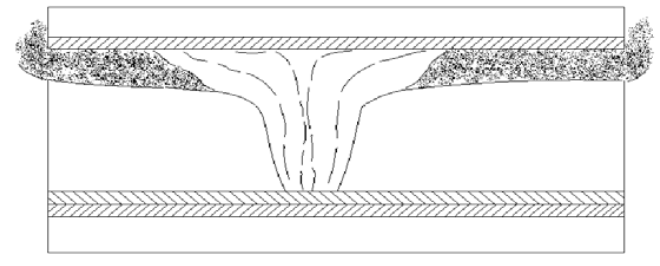

Figure 7. An illustration of observations of a corridor flow for heptane ventilation controlled pool fires [7].



Figure 8 Correlation of mass pyrolysis data with opening ventilation factor for the corridor experiments in [6] for two pan fires of area $112 \mathrm{~cm}^{2}$ and $225 \mathrm{~cm}^{2}$ in consistency with Equ.5 
Using a similar approach, the pyrolysis rate relates to the air inflow by,

$$
\dot{m}_{F}=0.125 \dot{m}_{a}
$$

for the ventilation controlled regime as derived after combining Equations 7 and $8 \mathrm{~b}$.

This relation should be compared with Equ.6b for a cubic like enclosure where the respective proportionality coefficient is 0.22 . The reduction of proportionality coefficient by about half is due to the reduced energy feedback from both the flames and the hot layer because the temperature distribution is non-uniform in corridors compared to nearly uniform temperature in cubic like enclosures.

Finally, one should notice by comparison with Equ.6c that in corridors no excess pyrolysate exists if the stoichiometric ratio is less than $1 / 0.125=8$.

The pyrolysis rate and the air inflow rate do not depend only on the room geometry as discussed following Equs.7, 8c and 8d and as confirmed by other recent work $[9,10]$. They also depend on the location of the opening on a wall of the enclosure [9], because the mixing conditions (ranging from uniform to layered) may drastically change with these parameters. The difference concerning air inflow rates between cubic like and corridor enclosures has also been previously discussed using dimensional analysis by Phil Thomas [11].

\section{CONCLUSIONS}

The major conclusions of the present work are:

1. A global energy balance in an enclosure provides a semi-quantitative picture of the flow and pyrolysis rates.

2. In ventilation controlled conditions, all incoming air is consumed. An appropriate energy balance including all heat losses can provide a uniform temperature for cubic like enclosures, see Equ.6g.

3. The air inflow rate dependence on the ventilation factor changes as the temperature distribution in the enclosure changes from uniform (rectangular room, Equ.1) to layered (corridor, Equ.8c).

4. In an enclosure, two temperature regions exist: a higher one near the combustion volume and a lower one in the rest of the enclosure. Heat fluxes will depend on the temperature and smoke concentration fields. A conservative estimate for radiative heat fluxes can use the higher temperature and optically thick conditions.

5. From the analysis of experimental data, it has been concluded that he pyrolysis rate dependence on the air inflow rate changes as the temperature distribution in the enclosure changes from uniform (rectangular room, Equ.6b) to layered (corridor, Equ.8d).

6. For some fuels depending on the mass air to fuel stoichiometric ratio no excess pyrolysate exists, compare with Equ.6d for cubic like, and discussion following Equ.8d for corridor enclosures. In this case, no flames would extend outside the enclosure.

7. The air inflow rate when mass pyrolysis rate is maximum varies significantly with the heat flux from the flames and the effective area of pyrolysis as discussed 
following Equs.6e and $6 \mathrm{f}$. This the weakest link in the current analysis requiring further investigation

8. For ventilation controlled fully involved enclosure fires, the heat release rate of the flames outside the enclosure due to the excess pyrolysate would be $\left(\dot{m}_{F}-\frac{\dot{m}_{a}}{S}\right) \Delta H_{c}$. This heat release rate determines the flame height of emerging flames and affects the heat fluxes to the external wall. Note that flames can be sufficiently long to extend outside the enclosure even for fuel controlled burning conditions as it was shown in [6].

\section{ACKNOWLEDGEMENTS}

Many thanks to the following people who provided great assistance in this project: Xijuan Liu, Mary Delichatsios and Y. Ohmiya

\section{REFERENCES}

1. Kawagoe, K and T Sekine,. "Estimation of Fire Temperature Rise Curves in concrete Buildings (Part 2)" Transactions of the Architectural Institute of Japan, No. 85, 86, 1963.

2. Walton, D.W. and Philip H. Thomas, "Estimating Temperatures in Compartment Fires" SFPE Handbook of Fire Protection Engineering, 3-134, 1995, ( where many other relevant references are cited).

3. Delichatsios, M.A. and X. Liu "Heat fluxes and excess pyrolysate in fully developed enclosure fires for external wall fire performance evaluation" CIB World Building Congress, April 2001, Wellington, New Zealand, aslo submitted to Fire Safety Journal, 2002.

4. Ohmiya, Y., T. Tanaka, T. Wakamatsu "A Room Fire Model for Predicting Fire Spread by external Flames", Fire Science and Technology , 18, 1, pgs 11-21, , 1998.

5. Tewarson, A. Generation of Heat and Chemical Compounds in Fires, SFPE Handbook , $2^{\text {nd }}$ Edition, 1995

6. Ohmiya Y., S. Yusa, Jun-Ichi Suzuki, K. Koshikawa and M. A. Delichatsios "Aerothermodynamics of Fully Involved Enclosure Fires Having External Flames" Submitted for ublication, May 2002.

7. Miyazaki, S and Y. Watanabe, "An Experimental Study on Fire Phenomena of Liquid Fuel In A Small-Sized Tunnel Burning Behaviour Of N-Heptane (Part 1)" paper B-14 and "An Experimental Study On Fire Phenomena Of Liquid Fuel In A Small-Sized Tunnel Relation Between Inside Temperature Of The Tunnel And Burning Rate Of N-Heptane (Part 2)" paper A-15, 1998

8. Delichatsios, M.A. and X. Liu "Temperatures and Heat Fluxes In Corridors Owing to Room Fires" InterFLAM, pg 1323., September 2001.

9. Thomas,Ian R. and Ian D. Bennets. "Fires in Enclosures with Single Ventilation Openings:- Comparison of Long and Wide Enclosures", Fore Safety ScienceProceedings of the Sixth International Symposium, p. 941, 1999.

10. Cooke, GME, "Tests to Determine the Behaviour of Fully Developed Natural Fires in a Large Compartment”, BRE, FRS Fire Note 4., 1998. 
11. Thomas, P.H., "Two dimensional Smoke Flows from Fires in Compartments: Some Engineering Relationships", Fire Safety Journal, 18, 125-137, 1992.

12. Thomas, P.H and Bullen,M.L. "Compartment Fires with Non-Cellulosic Fuels"! $7^{\text {th }}$ Symposium(Int.) on Combustion,Leeds,UK,1978.

13. Quintiere,J.G., McCaffrey,B.J,Dan Braven,K “ Experimental and Theoretical Analysis of Quasi-steady Small-scale Enclosure Fires", "! $7^{\text {th }}$ Symposium(Int.) on Combustion,Leeds,UK, 1978.

14. Takeda, $\mathrm{H}$ and Akita, $\mathrm{K}$ "Critical Phenbomenon in Compartment Fires with Liquid Fuels ", ! $8^{\text {th }}$ Symposium(Int.) on Combustion,Leeds,UK, 1978.

15. Babrauskas, W. ,Wickstrom, U, "Thermoplastic Pool Compartmenmt Fire" Combustion and Flame, Vol. 25, 1976

16. Delichatsios,M.A., Orloff, L. and Delichatsios,M.M. “ The effects of Fuel Sooting tendency and the Flow on Flame Radiation in Luminous Turbulent Jet Flames “ Combust. Sci.and Tech. 84,199-215,1992.

\section{Nomenclature}

$A_{o} H_{o}^{1 / 2} \quad$ opening ventilation factor for a single opening, $\mathrm{m}^{5 / 2}$

$\mathrm{A}_{\mathrm{o}} \quad$ enclosure opening area, $\mathrm{m}^{2}$

$A_{F} \quad$ total fuel area, $\mathrm{m}^{2}$

$\mathrm{A}_{\mathrm{T}} \quad$ total enclosure area, $\mathrm{m}^{2}$

C dimensionless constant for equations $8 \mathrm{~b}$ and $8 \mathrm{c}$

$C_{p} \quad$ specific heat of air, $\mathrm{kJ} / \mathrm{kg} / \mathrm{K}$

$\mathrm{H}_{\mathrm{o}} \quad$ enclosure height, $\mathrm{m}$

$\mathrm{k}_{\mathrm{w}} \quad$ wall conductivity, $\mathrm{kW} / \mathrm{m} / \mathrm{K}$

$\mathrm{L} \quad$ latent heat of pyrolysis, $\mathrm{kJ} / \mathrm{kg}$

$\dot{m}_{F} \quad$ fuel mass pyrolysis rate, $\mathrm{kg} / \mathrm{s}$

$\dot{m}_{a} \quad$ mass inflow rate in the enclosure, $\mathrm{kg} / \mathrm{s}$

$\dot{q}_{r}^{\prime \prime} \quad$ heat flux to the fuel from the flames and hot gases, $\mathrm{kW} / \mathrm{m}^{2}$

$\mathrm{S} \quad$ air to fuel mass stoichiometric ratio

$T_{g} \quad$ gas temperature in the enclosure, $\mathrm{K}$

$T_{o} \quad$ initial ambient temperature, $\mathrm{K}$

$T_{p} \quad$ material pyrolysis temperature, $\mathrm{K}$

Greek Symbols

$3000 \chi_{A} \quad$ heat release rate per mass of air consumed, where $\chi_{A}$ is the combustion efficiency

$\delta_{\mathrm{w}} \quad$ wall thickness, $\mathrm{m}$

$\Delta H_{v}$ heat of pyrolysis per mass of fuel equal to latent plus sensible heat to raise the surface temperature to the fuel pyrolysis temperature, $\mathrm{kJ} / \mathrm{kg}$

$\Delta H_{c} \quad$ heat of combustion per unit fuel mass, $\mathrm{kJ} / \mathrm{kg}$

$\chi_{A} \quad$ combustion efficiency 